\title{
Aspects of morbid jealousy
}

\section{Michael Kingham \& Harvey Gordon}

Abstract Morbid jealousy is encountered in general, old age and forensic psychiatry, and clinicians in each specialty should be familiar with its recognition and management. As well as clinical matters, the issue of risk to the patient and others is prominent in the consideration of morbid jealousy. Hospitalisation is sometimes required, the use of compulsory admission is not infrequent and treatment in secure settings is occasionally warranted. This review addresses the nature of morbid jealousy, its psychopathology, diagnostic issues, associations, risks and management.

Jealousy is a common, complex, 'normal' emotion. The Oxford English Dictionary defines the word jealous as 'feeling or showing resentment towards a person one thinks of as a rival'. This definition indicates that it is the belief in the presence of rivalry that is the key issue, and that whether or not such a rivalry truly exists is less important. Jealousy within a sexual relationship has clear advantages in evolutionary terms: behaviour that ensures the absolute sole possession of a partner allows the propagation of one's own genes at the expense of those of a true rival (Daly et al, 1982). However, when the belief in rivalry is mistaken, much time and effort may be wasted in attempting to eliminate a false threat.

Morbid jealousy describes a range of irrational thoughts and emotions, together with associated unacceptable or extreme behaviour, in which the dominant theme is a preoccupation with a partner's sexual unfaithfulness based on unfounded evidence (Cobb, 1979). It is noteworthy that individuals may suffer from morbid jealousy even when their partner is being unfaithful, provided that the evidence that they cite for unfaithfulness is incorrect and the response to such evidence on the part of the accuser is excessive or irrational. Healthy people become jealous only in response to firm evidence, are prepared to modify their beliefs and reactions as new information becomes available, and perceive a single rival. In contrast, morbidly jealous individuals interpret conclusive evidence of infidelity from irrelevant occurrences, refuse to change their beliefs even in the face of conflicting information, and tend to accuse the partner of infidelity with many others (Vauhkonen, 1968).
In popular usage, morbid jealousy has been dubbed the 'Othello syndrome', with reference to the irrational jealousy of Shakespeare's Othello (Todd \& Dewhurst, 1955). This is misleading, as it suggests that morbid jealousy is a unitary syndrome. Demonstrably, this is not the case, and morbid jealousy should be considered to be a descriptive term for the result of a number of psychopathologies within separate psychiatric diagnoses (Shepherd, 1961).

\section{Epidemiology}

The prevalence of morbid jealousy is unknown, as no community survey exists. It has been regarded as a rare entity (Enoch \& Trethowan, 1979), but most practising clinicians encounter it not uncommonly. They may miss cases that present with other dominating psychopathologies and will never see those cases that do not result in psychiatric referral.

In a sample of 20 cases of delusional jealousy studied in California, Silva et al (1998) found that the average age at onset of psychosis was 28 years and that delusional jealousy began an average of 10 years later. The oldest patient was 77 years of age. Of the 20 individuals, 19 were male. Eighty per cent of the sample were married and living with their spouses. The ethnicity of the sample reflected the ethnicity of the population, so that no correlation between ethnicity and delusional jealousy was observed.

Statistics on geographical prevalence and ethnicity are not available, although scientific papers dealing with morbid jealousy have been

Michael Kingham is currently a locum consultant forensic psychiatrist at the Trevor Gibbens Unit in Kent (Trevor Gibbens Unit, Hermitage Lane, Maidstone, Kent ME16 9QQ, UK), having recently worked as a specialist registrar at Broadmoor Hospital. Harvey Gordon is a consultant forensic psychiatrist for the South London and Maudsley NHS Trust and an honorary lecturer in forensic psychiatry at the Institute of Psychiatry, London. He has also worked at Broadmoor Hospital. 
published by European, North American and Australasian authors. Bhugra (1993) suggests that there are societies less prone to jealousy because they place no value on the exclusive ownership of a partner.

\section{Psychopathology and diagnosis}

Mullen (1990) considered morbid jealousy to be associated with four features: first, that an underlying mental disorder emerges before or with the jealousy; second, that the features of the underlying disorder coexist with the jealousy; third, that the course of morbid jealousy closely relates to that of the underlying disorder; and fourth, that the jealousy has no basis in reality. However, it can also be argued that delusions of infidelity can still be pathological, even where a partner is unfaithful, because there is no logical evidence being adduced for the beliefs.

In morbid jealousy, the content of the psychopathological experience is the preoccupation with a partner's sexual infidelity. The most commonly cited forms of psychopathology in morbid jealousy are delusions, obsessions and overvalued ideas.

\section{Delusions}

Some authors equate morbid jealousy with a delusional state (e.g. Enoch \& Trethowan, 1979) (Box 1). Shepherd (1961) pointed out that the commonly used term 'delusion of jealousy' is a misnomer and that the key psychopathology is a delusion of (the partner's) infidelity. Associated beliefs may include the morbidly jealous subject's suspicion that he or she is being poisoned or given substances to decrease sexual potency by the partner, or that the partner has contracted a sexually transmitted disease from a third party, or is engaging in sexual intercourse with a third party while the subject sleeps. These are persecutory delusions, and the delusion of infidelity itself may be viewed similarly.

Delusions of infidelity may be the initial presentation of schizophrenia, or appear as new features within an established psychosis. Delusional jealousy is a subtype of delusional disorder as described by DSM-IV (American Psychiatric Association, 1994) and ICD-10 (World Health Organization, 1992). In these cases, delusions of infidelity exist without any other psychopathology and may be considered to be morbid jealousy in its 'purest' form. The delusions are expressed coherently and are elaborated thoughtfully and plausibly, in contrast to the bizarre associations characteristically made in schizophrenia. Memories are revised and reinterpreted and the partner's
Box 1 Characteristics of delusions in morbid jealousy

Delusions are:

- the individual's own thought

- egosyntonic

- regarded as true

- not resisted

present actions are misinterpreted to produce an absolute conviction of repeated betrayal (Mullen, 1991).

Affective disorders complete the functional illnesses associated with delusions of infidelity. Depression, with accompanying subjective feelings of inadequacy and failure, may give rise to delusional jealousy or it may follow its onset. It may be difficult to decide whether depression is primary or secondary (Cobb \& Marks, 1979). In one study of morbid jealousy, depression was present in more than half of the patients (Mullen \& Maack, 1985).

Organic brain disorders may give rise to delusions of infidelity. In their series, Mullen \& Maack (1985) found that almost $15 \%$ of individuals with morbid jealousy had an organic psychosyndrome with which the jealousy appeared associated. Cobb (1979) recorded that morbid jealousy may be present with all types of cerebral insult or injury.

\section{Obsessions}

In obsessional jealousy, jealous thoughts are experienced as intrusive and excessive, and compulsive behaviours such as checking may follow. Such patients recognise that their fears are without foundation and are ashamed of them (Box 2) (Shepherd, 1961; Mooney, 1965; Cobb \& Marks, 1979, Bishay et al, 1989; Stein et al, 1994). Egodystonicity (the distress caused by thoughts that are unwanted and viewed as contrary to conscious wishes) characteristically varies considerably between patients, and a continuum from obsessional to delusional morbid jealousy has therefore been suggested (Insel \& Akiskal, 1986).

Box 2 Characteristics of obsessions in morbid jealousy

Obsessions are:

- the individual's own thought

- egodystonic

- acknowledged to be senseless

- usually resisted 
Box 3 Distinguishing normal from obsessional jealousy (Marazziti et al, 2003)

The following are more extreme in obsessional jealousy:

- time taken up by jealous concerns

- difficulty in putting the concerns out of the mind

- impairment of the relationship

- limitation of the partner's freedom

- checking on the partner's behaviour

In a study of young adults, Marazziti et al (2003) identified a number of factors that, when taken to the extreme, distinguish normal from obsessional jealousy (Box 3).

Mullen (1990) considered an obsessional disorder at the core of morbid jealousy to be a 'true rarity'. Cobb (1979) concluded that, although a distinction was occasionally difficult to make, the categories of 'psychotic' (delusional) and 'neurotic' jealousy contained similar proportions (each between onethird and one-half).

\section{Overvalued ideas}

Sims (1995: pp. 17 \& 368) raised the possibility that morbid jealousy could take the form of an 'overvalued idea' (Box 4), that is, an acceptable, comprehensible idea pursued by the patient beyond the bounds of reason. The idea is not resisted and, although it is not a delusion, the patient characteristically attaches utmost importance to investigating and maintaining the partner's fidelity at great personal disadvantage and to the distress of the partner.

Overvalued ideas of morbid jealousy are described in the paranoid personality disorders classification of DSM-IV and ICD-10.

The prevalence of this subtype of morbid jealousy is unknown, and it is likely that a substantial proportion of people with these traits never present to mental health services. It is probable that in some recognised cases, what is identified as an overvalued

\section{Box 4 Characteristics of overvalued ideas in morbid jealousy}

Overvalued ideas are:

- the individual's own thought

- egosyntonic

- amenable to reason

- not resisted idea is underestimated and really represents a delusion.

Borderline personality organisation (Dutton, 1994) is an important potential predisposing condition in any form of morbid jealousy (Box 5). It may be especially so in individuals with a paranoid personality, which gives rise to overvalued ideas of infidelity.

\section{Comorbidity}

Comorbidity is usual in morbid jealousy, and the 'pure' forms are rare. The presence of various combinations of comorbidity with personality disorder, mental illness and substance misuse can produce a very complicated picture. For example, a person with a paranoid personality disorder may become preoccupied with and distressed by jealous overvalued ideas, develop a delusion of infidelity and turn to substance misuse in an attempt at selfmedication.

\section{Theories of development}

\section{Psychodynamic}

Freud considered that delusional jealousy represented projected latent homosexuality, in terms of 'I do not love him for she loves him' (Freud, 1922). Klein highlighted the rivalry between son (the jealous individual) and father (the supposed rival) in the Oedipus complex (Klein, quoted in Shepherd, 1961). Seeman (1979) suggested that the role of competitiveness is significant, along with projective mechanisms and identification with the rival.

Attachment theory has been advanced to explain male jealousy, anger and assaults against the female partner within intimate relationships (Dutton et al, 1994; Box 5). Insecurely attached individuals,

Box 5 Characteristics of individuals with borderline personality organisation (after Dutton et al, 1994)

- Negative self-model

- Feelings of unworthiness

- Identity diffusion (poorly integrated sense of self and of significant others)

- Anxiety about rejection and abandonment in close relationships

- Perception of unfaithfulness in partner

- Affective instability, including anger within the intimate relationship and jealousy

- Primitive defence mechanisms, especially projection of unacceptable impulses 
especially those of the fearful and preoccupied type, may be at increased risk of becoming anxious about their partner's attachment to them. Insecure attachment style correlates strongly with borderline personality organisation.

\section{Cognitive}

Enoch \& Trethowan (1979) viewed a sense of inadequacy, oversensitivity and insecurity to be major predisposing factors in the development of morbid jealousy. In their cognitive formulation, Tarrier et al (1990) proposed that people with these characteristics tend to make systematic distortions and errors in their perceptions and interpretation of events and information, so that a precipitating event gives rise to faulty assumptions and provokes morbid jealousy. These ideas resemble those described by attachment theory, especially in the context of borderline or paranoid personality organisation.

Docherty \& Ellis (1976) documented three morbidly jealous men, each of whom, during adolescence, saw his mother engaged in extramarital sexual activity. Although the authors interpreted the morbid jealousy of these men in psychodynamic terms (relating to Oedipal issues), their suggestion for therapy to combat cognitive distortion is in line with cognitive-behavioural therapy.

\section{Sexual dysfunction}

It has also been suggested that morbid jealousy may arise in response to reduced sexual function. Cobb (1979) drew attention to the elderly man whose waning sexual powers are insufficient to satisfy a younger wife. Vauhkonen (1968) described sexual dysfunction per se to be important, but whether this was considered to be primary or secondary is unclear. Todd et al (1971) reported that real or imaginary hypophallism may give rise to feelings of inferiority and lead to the development of morbid jealousy.

\section{Marital and social factors}

In cultures in which partners are treated as possessions, jealousy is often considered to be a normal part of sexual relationships and it may therefore be seen as an understandable (although undesirable) explanation for marital tension. Gender-role behaviour in which the male partner is dominant and the female submissive, in which there is a sense of sexual ownership, is generally tolerated.
In highly conservative cultures, any evidence of autonomous or independent activity by a partner may be interpreted as evidence of infidelity and punished. Jealousy in this context may be used to justify violence towards a partner who is perceived as unfaithful.

For these reasons, it is important to be sceptical about claims by patients who are violent towards their partners in the context of jealousy that their victims (usually female) have provoked or actively encouraged them to be jealous.

The possibility of significant mental disorder in the patient's partner should be considered. In one instance, as a husband's delusional jealousy was successfully treated, the wife developed a paranoid psychosis, which receded as the husband's jealousy returned (Turbott, 1981). Abnormal jealousy in homosexual patients has also been described (Gordon et al, 1997). Economic depression has been associated with increased incidence of delusional jealousy (Shepherd, 1961).

\section{Associated alcohol and drug use}

Alcohol misuse has a well-recognised association with morbid jealousy (Shepherd, 1961). In two studies, morbid jealousy was present in $27 \%$ and $34 \%$ respectively of men recruited from alcohol treatment services (Shrestha et al, 1985; Michael et al, 1995).

Given the prevalence of harmful and dependent use of alcohol in the UK, these figures suggest that morbid jealousy is not rare.

Some authors consider alcohol to exacerbate existing morbid jealousy, but rarely to be a primary cause (Langfeldt, 1961; Shepherd, 1961; Cobb, 1979). This is disputed by Michael et al (1995), who described 65 of 71 male subjects as developing morbid jealousy following, and presumably secondary to, alcohol dependence.

Amphetamine and cocaine use can give rise to delusions of infidelity that may persist after intoxication ceases (Shepherd, 1961). One case report described a man prescribed dexamphetamine for adult attention-deficit hyperactivity disorder who developed morbid jealousy (Pillai \& Kraya, 2000).

A likely explanation for morbid jealousy that is present apparently only at times of intoxication is that it exists at other times but in an inhibited state. The disinhibition that accompanies intoxication results in its manifestation. The individual who turns to substance use may be attempting to cope with the symptoms of either borderline or paranoid personality organisation, with accompanying jealousy. 


\section{Risks associated with morbid jealousy \\ Confirmatory behaviours}

Once suspicions regarding the partner's fidelity are established, they quickly become preoccupying. Overt behaviours to investigate suspicions and preoccupations are common and evident to all involved. They include interrogation of the partner, repeated telephone calls to work and surprise visits, stalking behaviour, or hiring a private detective to follow the partner. Jealous individuals may search the partner's clothes and possessions, scrutinise diaries and correspondence, and examine bed linen, underclothes and even genitalia for evidence of sexual activity. They may hide recording equipment to detect clandestine liaisons, and some go to extreme lengths, including violence, to extract a confession from their partner.

The accused partner is assumed to be guilty until evidence of innocence is found, but this cannot materialise. Heroic efforts to prove innocence or disprove guilt must fail, as irrational preoccupations cannot be refuted rationally (Shepherd, 1961; Mooney, 1965; Seeman, 1979).

\section{Harm to self}

Suicidal ideation is not uncommon in morbid jealousy, given the association with depression and substance misuse. Aggressive challenging of the partner may be followed by intense remorse during which suicidal action may occur (Shepherd, 1961). In a UK population, Mooney (1965) found that $20 \%$ of morbidly jealous individuals had made suicide attempts. Where jealousy gives rise to fatal violence against the partner, this may be followed by suicide (West, 1965).

\section{Risk to others}

Violence may occur in any relationship marred by jealousy, although the risk may be greater in morbid jealousy (Mullen, 1990). Culturally, jealousy may be used to justify violence towards partners, and in some courts of law it can even be used as the basis of a provocation defence. Victims of homicide are most likely to be current or ex-partners; this is true for both male and female perpetrators.

Dell (1984) concluded that 'amorous jealousy/ possessiveness' accounted for $17 \%$ of all cases of homicide in the UK. Mowat (1966) reported on 110 morbidly jealous subjects who had killed or committed serious assaults and been admitted to a British forensic psychiatric facility. In 94 cases, the victim had been the partner. In Mooney's (1965) series, $14 \%$ of morbidly jealous individuals were considered to have made 'homicidal attempts', the majority against the accused partner.

Repeated denials of infidelity may provoke extreme anger and violence. Alternatively, the longsuffering partner, plagued by repeated crossexamination and accusations of infidelity, may yield and give a false confession, provoking a violent rage in the jealous individual.

Domestic violence is a common result of jealousy, normal or morbid. According to the British Crime Survey, $23 \%$ of women and $15 \%$ of men have been physically assaulted by their partners (MirrleesBlack, 1999). Domestic violence is associated with increased risk of death at the hands of the perpetrator. It is also associated with morbid jealousy in the context of borderline personality organisation in males (Dutton, 1994).

Mullen \& Maack (1985) found in their UK series that more than half of morbidly jealous individuals physically assaulted their partner, although none had come to the attention of the criminal justice system. Morbidly jealous men were more likely to attack their partners than were morbidly jealous women and they tended to inflict more serious injuries.

In their US sample of 20 individuals with delusional jealousy, 19 of whom were male, Silva et al (1998) found that 13 had threatened to kill their spouse because of alleged infidelity - of these, 9 had actually attacked their spouse. Overall, 12 had harmed their spouse, 3 of them using a weapon. The presence of paranoid delusions and command hallucinations to injure the spouse were associated with violence, suggesting that individuals with delusional jealousy who perpetrate violence may be driven directly by psychotic phenomena. Alcohol consumption was also associated with a higher risk of assault.

Accusations may be made and violence directed towards a third party believed to be the partner's lover, the 'paramour' (Tarrier et al, 1990). Seven out of 110 victims of homicide or serious assault were supposed paramours in Mowat's study (1966). More than $50 \%$ of the alleged paramours in Silva et al's (1998) study of delusional jealousy were known to the subject. However, no serious threats of harm or incidents of violence were made against them.

The gender difference in physical assault against partners found by Mullen \& Maack (1985) is difficult to quantify because violence by women against men may be underreported. Similarly, given the problems in distinguishing accurately between delusions, obsessions and overvalued ideas, it is difficult to estimate the relative risk of interpersonal violence 
of each form. Nevertheless, psychotic drive in delusional jealousy seems to be a particularly important association, as it is generally in linking psychotic conditions and violent actions. Overall, morbid jealousy indicates a paranoid state of mind and therefore is likely to be associated with a high risk of violence.

\section{Risk to children}

Children in the household may suffer emotional and physical abuse as a result of the actions of a morbidly jealous parent. They may witness arguments and physical violence between their parents or be injured accidentally during assaults. They may be employed by the morbidly jealous partner to spy on a parent. They may even see a homicide or suicide in which a parent is the victim.

\section{Other risks}

Partners of morbidly jealous people may develop mental disorder, including anxiety and depression, or may turn to substance misuse (Tarrier et al, 1990). Vauhkonen (1968) described two cases in which jealousy became apparent only after the partner had made suicide attempts in response to persistent unreasonable accusations. Rarely, partners may respond violently themselves to repeated confrontations. Severe psychological damage to individuals, couples and families arising from morbid jealousy is discussed by Cobb (1979).

\section{Management of morbid jealousy}

\section{Assessment}

Assessment of morbid jealousy requires a wideranging approach (Box 6). Careful history-taking should be employed, and, if possible, both partners should be interviewed separately and together. The issue of jealousy should be approached tactfully, as the jealous individual may believe that the partner's alleged infidelity is creating the difficulties, not their own jealousy. It is important to complete a full psychiatric history and mental state examination, looking carefully at the phenomenology of the jealousy. It may be possible to distinguish between jealousy that is delusional, obsessional or an overvalued idea, and this may be significant in terms of risk. Evidence of associated mental illness and substance misuse should be carefully elicited. It is recommended that more than one interview be conducted to assess the marital relationship, and that a sexual and domestic violence history be taken from both partners, who should be seen separately as well as together.

\section{Box 6 Assessment of morbid jealousy}

Take a full psychiatric history, including:

- affective and psychotic disorders

- threatened and perpetrated violence

- the quality of the relationship

- family constitution

- substance misuse

- collateral and separate history from spouse

Carry out a mental state examination, including:

- the form of morbid jealousy

- associated psychopathology

- consideration of organic disorder

Conduct a risk assessment for both partners, considering:

- suicide

- history of domestic violence

- history of interpersonal violence, including any third party (e.g. suspected rival)

- risk to children

Regarding risk, the issue of suicidal ideation should be raised with both partners. Enquiries about confrontations, arguments, threats and actual violence perpetrated by the jealous individual should be made, so that the risk of interpersonal violence, especially to the partner and any third party identified as a rival, can be assessed. The risk to children in the household should be considered, and protecting them is a paramount concern.

\section{Initial considerations following assessment}

It is wise to share information about risk with both partners. Consent should first be sought from the patient, unless the risk to another individual is serious and immediate, in which case confidentiality may be broken. All necessary steps should be taken to protect a potential victim: this may range from giving advice to that person to notifying the police. If there is a high risk of harm, the morbidly jealous individual should be admitted to hospital immediately. Child protection proceedings should be instituted if necessary.

If there is a history of violence, it should be made clear that physical abuse is unacceptable and illegal. Criminal and civil law (the Family Law Act 1996) provide protection against domestic violence, and victims may be advised to seek legal advice. Child protection proceedings should be initiated in accordance with the Children Act 1989 if there is cause to suspect that a child is suffering, or is likely to suffer, significant harm (Department of Health, 1999). 
Box 7 Management of morbid jealousy

Principles of management:

- Treat the mental disorder

- Manage the risk

Biological options:

- Antipsychotic medication

- Selective serotonin reuptake inhibitors

Psychosocial options:

- Treatment of any substance misuse

- Cognitive-behavioural therapy

- Couple therapy

- Dynamic psychotherapy

- Child protection proceedings

- Admission to hospital (compulsory detention if necessary)

- Geographical separation of the partners

\section{Treatment}

A range of biological and psychosocial options are available for the management of morbid jealousy. These include medication, psychotherapy and hospital admission (Box 7).

\section{Medication}

When occurring alone, as in a delusional disorder or in the context of schizophrenia, delusions of infidelity may respond to antipsychotic medication (Mooney, 1965; Byrne \& Yatham, 1989). Obsessional jealousy, whether part of a depressive illness or not, may respond to selective serotonin reuptake inhibitors (Lane, 1990; Gross, 1991; Stein et al, 1994).

\section{Psychosocial interventions}

Cognitive therapy is effective in morbid jealousy, mainly when obsessions are prominent (Cobb \& Marks, 1979; Bishay et al, 1989; Dolan \& Bishay, 1996). Also endorsed are couple therapy (Cobb, 1979) and individual dynamic psychotherapy (Seeman, 1979). Dynamic psychotherapy has a place in the treatment of morbidly jealous individuals in whom personality disorders with borderline and paranoid traits are present.

Substance misuse should be addressed where necessary, using standard accepted methods such as motivational interviewing.

\section{Admission to hospital}

When morbid jealousy gives rise to appreciable distress, a significant risk of harm or is not managed satisfactorily by out-patient treatment, admission to hospital may be necessary.
If morbid jealousy is refractory to treatment, geographical separation of the partners may be all that is effective (Shepherd, 1961). In-patient admission may bring about temporary cessation of morbid jealousy through separation, but - all other things being equal - it is likely to return when normal arrangements resume. With the assistance of a social worker, the victim may be advised to approach the local authority under the Housing Act 1996, in which individuals who suffer domestic violence are designated as homeless. Emergency accommodation is prioritised for women who are pregnant, have dependent children or are deemed to be vulnerable.

After separation, the morbidly jealous partner may continue to intrude upon and even stalk the victim, maintaining a sense of entitlement to the partner, seeking a reconciliation and expecting continuing fidelity. Among stalkers, those who have had a prior relationship with the victim may be most likely to act violently against them (Mullen et al, 2000). Legislation such as the Protection from Harassment Act 1997 can provide protection and should be recommended to those who suffer in this way (Royal College of Psychiatrists, 2002).

\section{Prognosis}

Generally, the prognosis for morbid jealousy depends on the underlying phenomenology, the existence of comorbid mental disorders and the response to therapy. Langfeldt (1961) and Mooney (1965) considered a third of their patients to have made significant improvement, but that those with psychotic disorders had a poorer prognosis. The possibility that morbid jealousy will recur is significant, and careful monitoring is warranted indefinitely. Scott (1977) reported a number of second homicides due to morbid jealousy following discharge from prison or release from special hospital after years of apparent well-being. It is not clear what treatment was provided for these individuals.

\section{Conclusions}

Morbid jealousy is a symptom rather than a diagnosis. It may take the form of a delusion, an obsession or an overvalued idea, or combinations of these. The nature of its form, and other features evident from the history and mental state examination, should reveal the underlying diagnosis - or diagnoses - and allow appropriate management. Undoubtedly, alcohol misuse is an important association, and any substance misuse should be treated as a priority. 
Morbid jealousy has the potential to cause enormous distress to both partners within a relationship and to their family. It carries with it a risk of serious violence and suicide. Clearly, early identification and treatment are most important to prevent serious harm, and vigilance should be maintained. Risk management includes hospital admission of morbidly jealous individuals where necessary, together with taking steps to protect potential victims. The modern clinician has a variety of drug treatments and psychosocial approaches with which to tackle the disorder, and the prognosis may not be as bleak as was once thought. Given the potential for tragic consequences, morbid jealousy is a symptom to be treated vigorously.

\section{References}

American Psychiatric Association (1994) Diagnostic and Statistical Manual of Mental Disorders (4th edn) (DSM-IV). Washington, DC: American Psychiatric Association.

Bhugra, D. (1993) Cross-cultural aspects of jealousy. International Review of Psychiatry, 5, 271-280.

Bishay, N. R., Petersen, N. \& Tarrier, N. (1989) An uncontrolled study of cognitive therapy for morbid jealousy. British Journal of Psychiatry, 154, 386-389.

Byrne, A. \& Yatham, L. N. (1989) Pimozide in pathological jealousy. British Journal of Psychiatry, 155, 249-251.

Cobb, J. (1979) Morbid jealousy. British Journal of Hospital Medicine, 21, 511-518.

Cobb, J. P. \& Marks, I. M. (1979) Morbid jealousy featuring as obsessive-compulsive neurosis: treatment by behavioural psychotherapy. British Journal of Psychiatry, 134 301-305.

Daly, M., Wilson, M. \& Weghorn, S. J. (1982) Male sexual jealousy. Ethology and Sociobiology, 3, 11-27.

Dell, S. (1984) Murder into Manslaughter. Oxford: Oxford University Press.

Department of Health (1999) Working Together to Safeguard Children. London: Stationery Office.

Docherty, J. P. \& Ellis, J. (1976) A new concept and finding in morbid jealousy. American Journal of Psychiatry, 133, 679683.

Dolan, M. \& Bishay, N. (1996) The effectiveness of cognitive therapy in the treatment of non-psychotic morbid jealousy. British Journal of Psychiatry, 168, 588-593.

Dutton, D. G. (1994) Behavioural and affective correlates of borderline personality organisation in wife assaulters. International Journal of Criminal Justice and Behavior, 17, 26-38.

Dutton, D. G., Saunders. K., Starsomski, A., et al (1994) Intimacy-anger and insecure attachment as precursors of abuse in intimate relationships. Journal of Applied Social Psychology, 24, 1367-1386.

Enoch, M. D. \& Trethowan, W. H. (1979) Uncommon Psychiatric Syndromes (2nd edn), pp. 25-40. Bristol: John Wright.

Freud, S. (1922) Some neurotic mechanisms in jealousy, paranoia and homosexuality. Reprinted (1953-1974) in the Standard Edition of the Complete Psychological Works of Sigmund Freud (trans. and ed. J. Strachey), vol. XVIII. London: Hogarth Press.

Gordon, H., Oyebode, O. \& Minne, C. (1997) Death by homicide in special hospitals. Journal of Forensic Psychiatry, 8, 602-619.

Gross, M. D. (1991) Treatment of morbid jealousy by fluoxetine. American Journal of Psychiatry, 148, 683-684.

Insel, T. R. \& Akiskal, H. S. (1986) Obsessive-compulsive disorder with psychotic features: a phenomenologic analysis. American Journal of Psychiatry, 143, 1527-1533.

Lane, R. D. (1990) Successful fluoxetine treatment of pathologic jealousy. Journal of Clinical Psychiatry, 51, 345-346.
Langfeldt, G. (1961) The erotic jealousy syndrome: a clinical study. Acta Psychiatrica Scandinavica, 36 (suppl. 151), 768

Marazziti, D., Di Nasso, E., Masala, I., et al (2003) Normal and obsessional jealousy: a study of a population of young adults. European Psychiatry, 18, 106-111.

Michael, A., Mirza, S., Mirza, K. A. H., et al (1995) Morbid jealousy in alcoholism. British Journal of Psychiatry, 167, 668-672.

Mirrlees-Black, C. (1999) Findings from a New British Crime Survey Self-completion Questionnaire. London: Stationery Office.

Mooney, H. B. (1965) Pathologic jealousy and psychochemotherapy. British Journal of Psychiatry, 111, 1023-1042.

Mowat, R. R. (1966) Morbid Jealousy and Murder. London: Tavistock.

Mullen, P. E. (1990) Morbid jealousy and the delusion of infidelity. In Principles and Practice of Forensic Psychiatry (eds R. Bluglass \& P. Bowden), pp. 823-834. London: Churchill Livingstone.

Mullen, P. E. (1991) Jealousy: the pathology of passion. British Journal of Psychiatry, 158, 593-601.

Mullen, P. E. \& Maack, L. H. (1985) Jealousy, pathological jealousy and aggression. In Aggression and Dangerousness (eds D. P. Farrington \& J. Gunn), pp. 103-126. London: Wiley.

Mullen, P. E. , Pathe, M. \& Purcell, R. (2000) Stalkers and their Victims. Cambridge: Cambridge University Press.

Pillai, K. \& Kraya, N. (2000) Psychostimulants, adult attention deficit and hyperactivity disorder and morbid jealousy. Australian and New Zealand Journal of Psychiatry, 34, 160-163.

Royal College of Psychiatrists (2002) Domestic Violence: Report of the Domestic Violence Working Group (Council Report CR102). London: Royal College of Psychiatrists.

Scott, P. D. (1977) Assessing dangerousness in criminals. British Journal of Psychiatry, 131, 127-142.

Seeman, M. (1979) Pathological jealousy. Psychiatry, 42 351-361.

Shepherd, M. (1961) Morbid jealousy: some clinical and social aspects of a psychiatric symptom. Journal of Mental Science, 107, 688-704

Shrestha, K., Rees, D. W., Rix, K. J. B., et al (1985) Sexual jealousy in alcoholics. Acta Psychiatrica Scandinavica, 72, 283-290.

Silva, J. A., Ferrari, M. M., Leong, G. B., et al (1998) The dangerousness of persons with delusional jealousy. Journal of the American Academy of Psychiatry and the Law, 26, 607623.

Sims, A. (1995) Symptoms in the Mind (2nd edn). London: WB Saunders.

Stein, D. J., Hollander, E. \& Josephson, S. C. (1994) Serotonin uptake blockers for the treatment of obsessional jealousy. Journal of Clinical Psychiatry, 55, 30-33.

Tarrier, N., Beckett, R., Harwood, S., et al (1990) Morbid jealousy: a review and cognitive-behavioural formulation. British Journal of Psychiatry, 157, 319-326.

Todd, J. \& Dewhurst, K. (1955) The Othello syndrome: a study in the psychopathology of sexual jealousy. Journal of Nervous and Mental Disease, 122, 367-374.

Todd, J., Mackie, J. R. M. \& Dewhurst, K. (1971) Real or imagined hypophallism: a cause of inferiority feelings and morbid sexual jealousy. British Journal of Psychiatry, 119, 315-318.

Turbott, J. (1981) Morbid jealousy - an unusual presentation with the reciprocal appearance of psychopathology in either spouse. Australian and New Zealand Journal of Psychiatry, 15, 164-167.

Vauhkonen, K. (1968) On the pathogenesis of morbid jealousy. Acta Psychiatrica Scandinavica Supplementum, 202, $2-261$.

West, D. J. (1965) Murder Followed by Suicide. London: Heinemann

World Health Organization (1992) The Tenth Revision of the International Classification of Diseases and Related Health Problems (ICD-10). Geneva: World Health Organization. 


\section{Multiple choice questions}

1 Morbid jealousy:

a is found in ICD-10 as a diagnostic classification

$\mathrm{b}$ is a symptom of a mental disorder

c is a disorder of content rather than of form

d may take different psychopathological forms

e is a paraphilia.

2 Morbid jealousy is a disorder of content, in which the form may be:

a a delusion

$\mathrm{b}$ an obsession

c a combination of a delusion and an obsession

d an illusion

e an overvalued idea.

3 Regarding morbid jealousy:

a it is found exclusively in the northern hemisphere

b it may be said to have afflicted Shakespeare's Othello

c it is otherwise known as de Clerambault's syndrome d it is otherwise known as Fregoli's syndrome

e homicide perpetrated in morbid jealousy is usually committed against the suspected rival.

4 Morbid jealousy:

a never affects women

$\mathrm{b}$ is a contraindication to admission to a general psychiatric ward

c is too rare to be of concern to general adult psychiatrists

d may be associated with significant interpersonal violence

e requires proof that the spouse is faithful to be a valid symptom.

5 Recognised associations of morbid jealousy include:

a amphetamine use

b an organic brain syndrome

c alcohol use

d schizophrenia

e low self-esteem.

\section{CANFOR}

\section{Camberwell Assessment of Need - Forensic Version}

\section{By Stuart Thomas, Mari-Anne Harty, Janet Parrott, Paul McCrone, Mike Slade and Graham Thornicroft}

CANFOR is a tool for assessing the needs of people with mental health problems who are in contact with forensic services. It is based on the Camberwell Assessment of Need, a widely used needs assessment for people with severe mental health problems. Needs are assessed in 25 areas of life and cover a broad range of health, social, clinical and functional domains. The book includes the rating scales, descriptions of how they were developed and their psychometric properties, administration details, a full training programme, guidance on scoring and blank assessment forms for photocopying. Versions for use in both research and clinical settings are included.

July 2003, 128pp, A4, spiral-bound, ISBN 1901242986 , $£ 75$

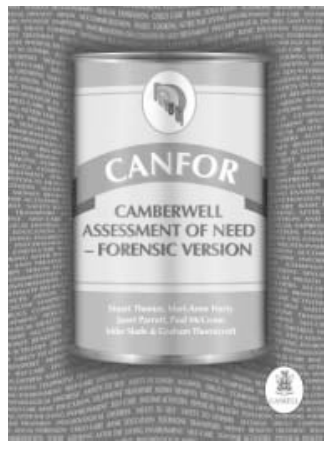

AVAILABLE NOW FROM:

Book Sales, Royal College of Psychiatrists, 17 Belgrave Square, London SW 1X 8PG, UK.

Tel: + 44 (0)20 72352351 ext 146. Fax: + 44 (0)20 72451231 .

Order online: www.rcpsych.ac.uk/publications 